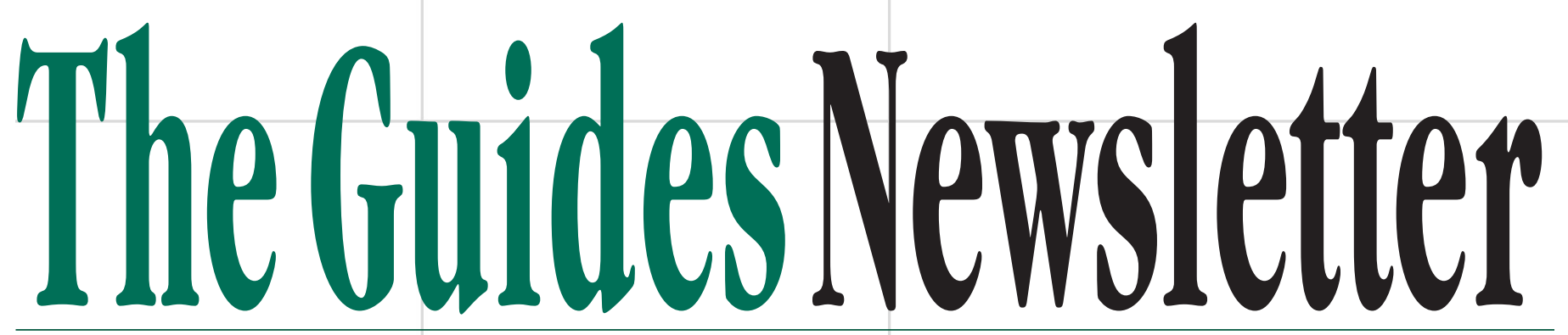

Expert advice, practical information, and current trends on impairment evaluation

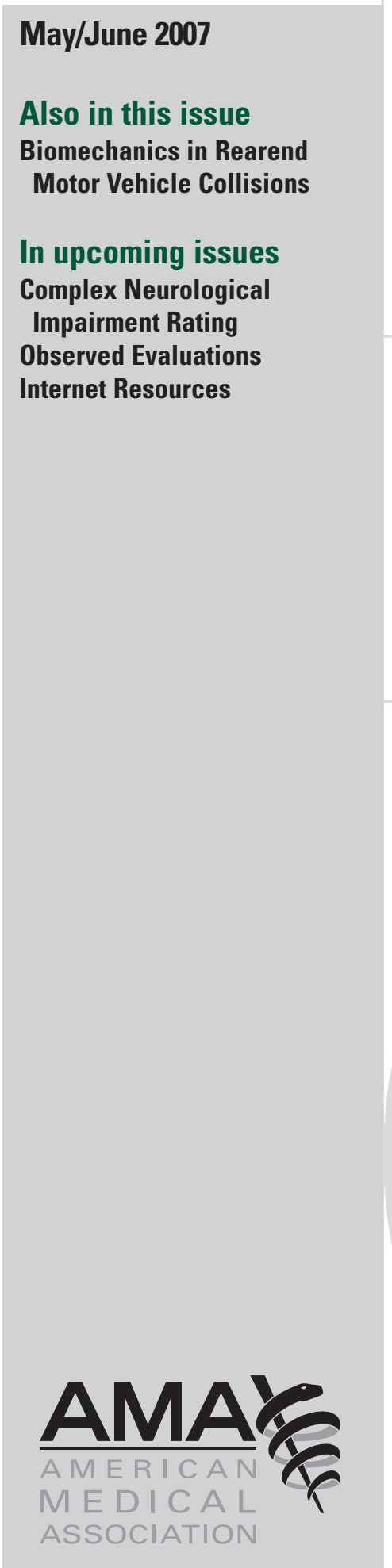

\title{
Cervical Whiplash: Assessment, Treatment, and Impairment Rating
}

by Alan L. Colledge, MD', Roger Pack, PT, OCS', and Christopher R. Brigham, $M D^{3}$, Charles N. Brooks, $M D^{4}$

Whiplash-associated disorder (WAD) refers to complaints attributed to a shearhyperextension then hyperflexion cervical injury, typically following a rearend motor vehicle collision (MVC). WAD is often challenging; and requires thoughtful assessment of diagnosis, causation, treatment, disability, maximal medical improvement, and impairment.

Neck pain and headaches are common following motor vehicle collisions, but there is significant variation in the duration of symptoms. Research suggests chronic whiplash symptoms should be the exception rather than the rule; and most cases of WAD resolve without permanent impairment. Many factors influence the development of chronic whiplash symptoms including preexisting pathology (physical and/or psychological), the severity of the injury, individuals' expectations of pain and disability following a collision, cultural influences, and psychosocial stressors.

Clinical evaluation and treatment guidelines derived from the best scientific knowledge available have failed to alter the epidemic of chronic whiplash symptoms in the United States and other countries, probably because they focus on biological treatment of WAD, ignoring cultural, psychological, and sociological influences. Given the questionable nature of much of the treatment rendered for WAD, this article will discuss appropriate care of whiplash, and a progressive approach to management, followed by impairment evaluation.

\section{Clinical Perspective}

Each year 5.5 million people are injured in motor vehicle collisions in the United States $^{1}$ including 2.9 million whiplash injuries. ${ }^{2}$ Most (78\%) patients report symptoms at the scene ${ }^{3}$, with $93 \%$ becoming symptomatic within 15 hours. ${ }^{4}$ Neck pain generally must be present for inclusion in any statistics or study on WAD. The next most common presenting complaint is headache (17-33\%), followed by upper extremity pain (6-13\%). ${ }^{5}$ Constant symptoms are reported by $43 \%$, while the remaining 57\% report intermittent complaints. ${ }^{6}$ Recovery from acute whiplash follows a predictable course, with the majority of uncomplicated WAD cases recovering in four to six weeks. ${ }^{3,7}$ However, there is significant variation in the prevalence of chronic

${ }^{1}$ Labor Commission, State Of Utah, Salt Lake City, Utah

${ }^{2}$ Spine and Sports Center, Provo, UT

${ }^{3}$ Brigham and Associates, Inc., Portland, Maine

${ }^{4}$ Bellevue, Washington

(c) 2007 American Medical Association.

No part of this publication may be reproduced, stored in a retrieval system, or transmitted, in any form or by any means, electronic, mechanical, photocopying, recording, or otherwise, without the prior written permission of the publisher. 


\section{The Guides Newsletter Advisory Board}

\section{Editor}

Christopher R. Brigham, MD

Portland, Maine

\section{Associate Editor}

James B. Talmage, MD

Cookeville, Tennessee

\section{Editorial Board}

Gunnar B.J. Andersson, MD

Chicago, Illinois

Charles N. Brooks, MD

Bellevue, Washington

Alan Colledge, MD

Salt Lake City, Utah

Lorne K. Direnfeld, MD, FRCP

Kahului, Hawaii

Leon H. Ensalada, MD, MPH

Waitsfield, Vermont

Mark Hyman, MD

Los Angeles, CA

Richard T. Katz, MD

St. Louis, Missouri

Edwin Klimek, MD

St Catharines, Ontario, Canada

Tom G. Mayer, MD

Dallas, Texas

Mark Melhorn, MD

Wichita, Kansas

Vert Mooney, MD

San Diego, California

Kathryn Mueller, MD

University of Colorado

James Robinson, MD

Seattle, Washington

Hal Stockbridge, MD

Olympia, Washington

Richard Strain, MD

Hollywood, Florida

Craig Uejo, MD

San Diego, California

Phil Walker, JD

San Francisco, California symptoms. Anywhere from $27 \%$ to $66 \%$ of WAD patients in the United States and Canada report chronic neck symptoms.4,6,8-10,12 Data from Lithuania, Greece, and Germany suggest chronic neck pain and headaches should be present at the same rate as seen in the general population, anywhere from $10 \%$ to $13 \%{ }^{8,9}$ Demolition derby drivers rarely develop chronic symptoms despite repeated exposure to similar forces during a single event. ${ }^{10,11}$ Since the forces on cervical spine are the same whether a given collision occurs in the United States,

Lithuania, Greece, Germany, or a demolition derby; a biological explanation of WAD alone cannot account of the variations in occurrence of chronic neck pain following an MVC.

Pain is a subjective experience influenced by biological, social, psychological, and other factors. Research shows that people will seek treatment if one of these influences exceeds a personal tolerance level. ${ }^{15-19}$ Immediately following a collision, biological factors predominate (Figure 1). The biological influence decreases with tissue healing to the point where, in the absence of social and psychological stimuli, symptoms usually resolve completely (Figure 2). However, if psychological or social issues exceed an individual's personal tolerance level, complaints persist despite the fact tissue healing has occurred (Figure 3).

\section{Figure 1}

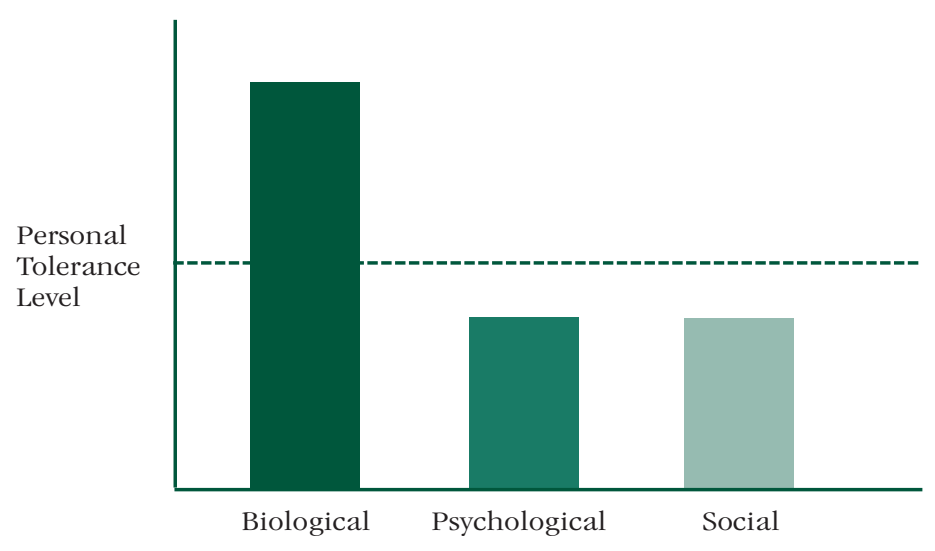

Figure 2

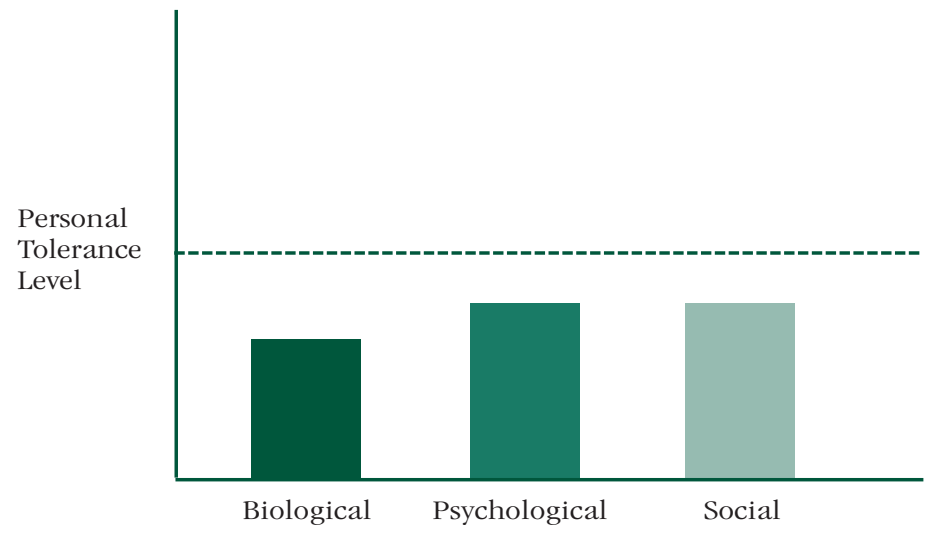




\section{Figure 3}

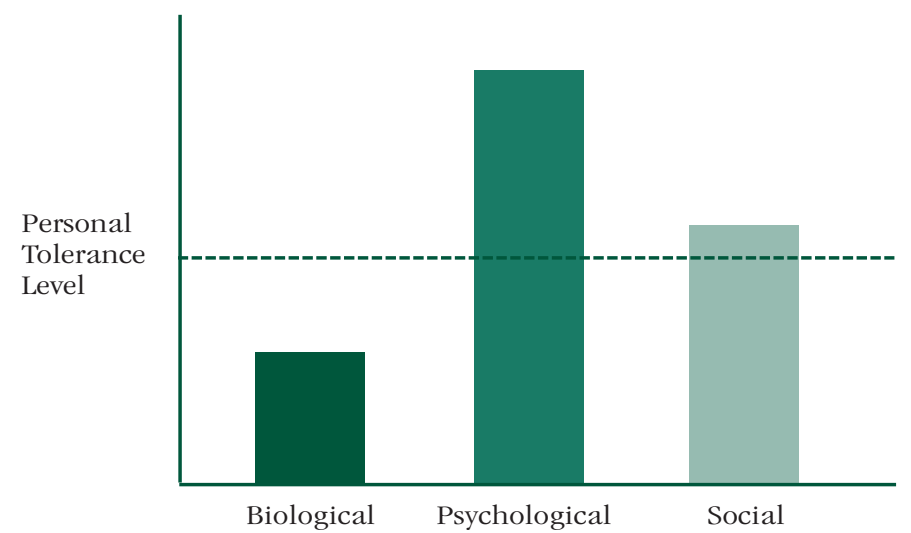

The "whiplash culture" present in some countries can influence the development of chronic neck pain and related symptoms following an MVC. Mass media communicates the symptoms, clinical course, and social acceptability of whiplash. Unfortunately, in their efforts to attract viewers/readers, and hence consumers for the products and services of advertisers, the media may resort to hyperbole and sensationalism which often distort reality. Due to increasing reliance on the media as the primary source of health information for many persons, inaccurate and inflammatory reports and advertisements may cause the expected pains after a collision to be perceived as a serious medical problem. This perception may lead to unnecessary disability and a desire for extensive evaluation and treatment, which many healthcare providers are only too willing to accommodate.

In fact, some caregivers base their practices on treating vehicular injuries and may intentionally or unintentionally instill within their patients an exaggerated impression of trauma underlying the presenting complaints. Unwarranted diagnostic studies and questionable treatments not only result in unnecessary costs, but together with sometimes ill-founded diagnoses, often instill within a patient or reinforce a preexisting belief that something is seriously wrong. This often leads to iatrogenic, or system-induced, disability, and further direct and indirect costs. Patients may be enticed into filing a lawsuit by advertisements from attorneys offering to protects their "rights" and obtain "just compensation" for their injuries. Sometimes it appears the patient will not recover until the claim or lawsuit is settled because to do so would jeopardize the monetary settlement or award.

Hence the current system for evaluating, treating, and compensating whiplash has created a confusing and complex web of care that often reinforces within the mind of the patient the generally erroneous impression that something is seriously wrong. The independent medical examiner or other physician asked to assess the necessity of treatment, evaluate disability, rate impairment, etc. is placed in the midst of these complexities. However, the evaluating physician must remain impartial, and needs to obtain and carefully analyze all relevant data.

Multiple factors determine the likelihood, type, and severity of bodily injury following a motor vehicle accident, which in turn influence the need for treatment, extent of disability, and likelihood of permanent residuals. These include the strength and elasticity of the occupant's tissues (muscle, tendon, ligament, bone, etc) and hence their ability to resist externally applied direct or indirect stresses. The evaluator should obtain information regarding the collision itself such as the pre-impact velocity (direction and approximate speed) of the vehicle(s) involved, type of collision (frontal, near or far side, rear, or rollover), the point of impact, location and amount of exterior and any interior damage to the vehicle(s), an estimate of the change in velocity of the subject vehicle, and any deployment of air bag(s). This information, combined with history from the occupant, subsequent physical findings, and results of imaging and perhaps other diagnostic studies, provides an understating of the mechanism and magnitude of injury. From the point of impact one can assume the principal direction of force. The mass of the vehicles along with an estimate of the target vehicle's change in velocity helps assess forces applied to the occupant. History or other evidence regarding occupant location within the vehicle, use of shoulder and/or lap belt(s), presence or absence and adjustment of a head restraint, what happened to him or her during the collision, head position at impact, and when the neck pain and any other complaints began are also relevant in determining the likelihood, location, and severity of injury.

\section{Treatment}

Aristotle said, “Treatment of the part should never be attempted without treatment of the whole. That is the error of our day, separation of the body from the soul." Unfortunately, that is precisely what clinical consensus guidelines have done by addressing only the biological aspects of WAD. Such guidelines, while doubtless wellintended and frequently well-researched, have focused on changing practice patterns, and thereby healthcare utilization. ${ }^{3,8}$ However, given the failure to incorporate the nonphysical aspects of WAD, it is not surprising the whiplash epidemic continues unabated despite the attempts of conscientious healthcare providers to implement these guidelines. Patients are more than physical pathology, and until guidelines address the biopsychosocial nature of whiplash no change will be seen in the rates of chronic pain and disability following vehicular collisions.

Permanent impairment cannot be assessed until the individual is at maximal medical improvement (MMI). Therefore it is essential to determine whether all treatment necessary to achieve MMI has been provided. However, many of the treatments provided for WAD are of questionable efficacy, and not necessary to achieve MMI. Hence the evaluating physician should be familiar with appropriate treatment for WAD. The military has extensive experience managing trauma and has developed a simple, comprehensive, treatment strategy that addresses the biopsychosocial nature of compensable injuries along with the unintended consequences of their assessment and treatment. The military's "forward treatment" methodology is reflected in the so-called SPICE model, the acronym standing for its five components: Simplicity, Proximity, Immediacy, Centrality, and Expectancy. ${ }^{15}$

Continued on page 8 


\title{
Biomechanics in Rearend Motor Vehicle Collisions
}

\author{
by Charles N. Brooks, $M D^{1}$ and Christopher R. Brigham, $M D^{2}$
}

Multiple factors determine the likelihood, type, and severity of bodily injury following a motor vehicle collision (MVC), which in turn influence the need for treatment, extent of disability, and likelihood of permanent impairment. Among the most important is "delta-v" $(\Delta v)$, the change in velocity due to an impact. Other factors include the strength and elasticity of the occupant's tissues (muscle, tendon, ligament, bone, etc) and hence their ability to resist externally applied direct or indirect stresses. For example, a 290-pound professional football player is understandably less likely to be injured in a rearend collision than a frail, elderly woman.

Body position at the time of impact is also an important factor. Due to inertia, the occupant of a stopped vehicle which is rearended initially remains stationary relative to the ground while the car or truck is accelerated forward. Relative to the vehicle, the occupant's head, neck, and to a lesser extent back then move rearward (with initial posterior shear on the neck followed by spinal extension), and later rebound forward (flexion). A person whose cervical and thoracolumbar spine are in a neutral or near neutral position (looking straight forward or in a rearview mirror) at impact is less likely to be injured than someone rotated leftward or rightward, as the facet joints are designed to accommodate flexion and extension in neutral, but to a much lesser extent when rotated.

Awareness of the impending collision has a protective effect given the ability of a vehicular occupant to brace, guard, or otherwise contract muscles in preparation for impact. Conversely, individuals with no forewarning of a collision are more likely to be symptomatic afterward. Persons restrained by shoulder and lap belts are generally less likely to be injured than unrestrained occupants.

Anderson et $\mathrm{al}^{1}$ investigated the effects of braking on both occupant and vehicle kinematics in low speed rearend collisions. They found very little difference between no braking and the "normal" braking of an unaware occupant, ie, "foot resisting automatic transmission, simulating braking at a stop light." This result was anticipated by the authors based on prior published research and films of occupant kinematics during such impacts. When rearended the driver's foot comes off the brake pedal. Even if the brakes are then reapplied, the collision, lasting anywhere from 80-150 milliseconds, is already over. Hence normal braking probably does not influence the incidence, type, or severity of injury in low speed rearend collisions.
A second scenario investigated by Anderson et al was "full" braking, the driver of the stopped vehicle being aware of and braced for the impending rearend impact, pressing firmly on the brake pedal. While foot pressure on the brake pedal was transiently reduced post impact, unlike normal braking, this resulted in a small but significant reduction in $\Delta v$, diminishing likelihood of injury. Even apart from other effects of bracing, which might be applicable to an aware passenger, full braking may push the driver rearward into the seat back and closer to the head restraint, resulting in better "coupling" therewith, and lower injury risk. The latter effect is not universal, however. Some drivers pull rearward on the steering wheel when maximally braking, tending to pull their torso forward, and probably offsetting the reaction to foot pressure, with no increased coupling.

The most important determinants of bodily injury are the accelerations ( $\mathrm{g}$ forces) to which an occupant is subjected, and their duration. The higher the acceleration, and longer it is sustained, the greater the likelihood of injury. Since $\Delta v$ (delta $v)$, the change in velocity of a vehicle, is the area under the acceleration vs. time curve, it combines both factors, and is a useful way to quantify impact severity. In fact, studies have repeatedly shown the collision parameter most closely related to occupant injury potential is $\Delta v^{2-5}$. The vehicle's change in velocity dictates the speed with which an occupant will strike, or be struck by, its interior, whether head restraint and seat back in a rearend collision; seat belts, steering wheel, and/or dashboard in a frontal impact; or lap belt and door panel with a near side impact. Whatever the interior structure, the faster the speed of interaction with the occupant, the higher the forces on his or her body, and greater the probability of injury.

Since human subject test results are available for low speed collisions, and tolerances known for various $\phi \mathrm{v}$ impacts, if a reasonably accurate estimate of the velocity change in a given MVC can be obtained, it is possible to predict the likelihood or severity of bodily injury. However, occupants of both the bullet (striking) and target (struck) vehicles and witnesses are notoriously poor estimators of speed. Those who perceive themselves the innocent victim of another's negligence often exaggerate the magnitude of a collision, while at fault drivers tend to minimize its severity. Hence, one should take such reports "with a grain of salt." Instead, when formulating an estimate of $\Delta v$ it is generally advisable to obtain objective data regarding the collision, eg, vehicle photographs, damage repair esti- 
mates, and the car's onboard computer if available. Subjective but presumably unbiased information sources include reports, if any, from witnesses, an investigating police officer, and/or ambulance personnel.

Based upon a literature review (see table below) Szabo et al concluded "The consensus of human subject research conducted to date is that a single exposure to a rear end impact with a $\Delta v$ of $5 \mathrm{mph}$ or less is unlikely to result in injury, assuming a reasonably healthy, restrained occupant in a relatively normal initial position, and the existence of a head restraint." ${ }^{6}$ g. ${ }^{7-12}$ At the midpoint of this range, a $\Delta v$ of 5 , head accelerations are about 10 to $15 \mathrm{~g}$. These accelerations are well below the threshold for head injury. ${ }^{13}$ In fact, the head can take up to 100 to $200 \mathrm{~g}$ for 10 to 20 milliseconds. There must be a $\Delta v$ of approximately 9 or 10 , and a hard head restraint, before one starts to see symptoms of head injury. In summary, even "mild head injury from low speed impacts appears unlikely in light of the published tolerance data in human subject testing results." ${ }^{14}$

Unlike unrestrained occupants in hi speed frontal collisions, knee contact with the dashboard or other portion of

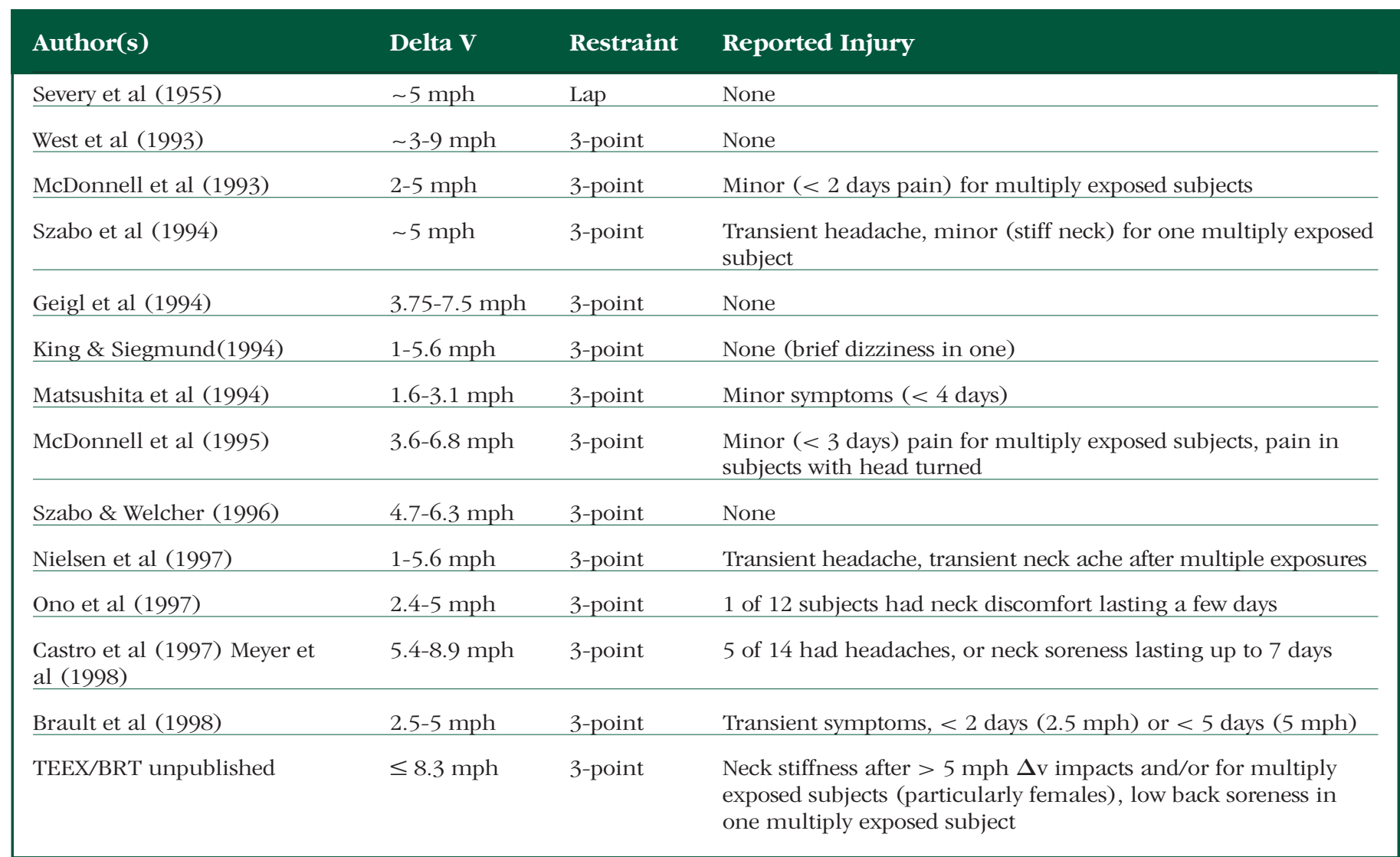

While, as implied, individual tolerances vary, a $\Delta v$ of 5-10 mph may be the "borderline" between no injury and injury. Many occupants subjected to a $\Delta v$ above $10 \mathrm{mph}$ would be injured, the probability thereof being proportional to the change in velocity.

As implied in the table, the most common symptom after a low speed rearend MVC is neck pain, followed by headache. Occasionally occupants in such collisions claim to have sustained a head injury. Is this plausible? As implied, in a rearend collision the occupant initially moves rearward relative to that vehicle, pushing further into the seat back, then strikes the head restraint (if any), and subsequently rebounds forward. Peak head accelerations for head restrained occupants in low speed rearend collisions ( $\Delta v^{\prime}$ s of 2 to $8 \mathrm{mph}$ ) range from about 2 to 20 the vehicle's interior is very unlikely for the restrained occupant of a car or truck rearended at low speed. ${ }^{15}$ Following the initial rearward motion, the knee returns to or about its initial position, being no more than $2.5 \mathrm{~cm}$ (1 inch) forward or $5 \mathrm{~cm}$ (2 inches) behind where it started, due to restraint provided by the lap belt. Furthermore, even if contact occurred, the velocity at which it did so would be low, less than normal walking speed.

Like contusions, ligamentous and meniscal injuries of the knee are very uncommon in rearend collisions. In a moderate to high speed frontal impact, foot-floorboard contact may result in longitudinal impaction on the lower limb, with compressive loads transmitted to the knee. If combined with rotation of the joint, a meniscal tear could 
result. Similarly, a driver's foot might slip off the brake pedal in a frontal impact, strike the footwell at an angle, with stress on and sprain of knee ligaments. On the other hand, in a rearend collision the occupant's foot moves away from the brake pedal or floorboard. The knee is unloaded, with no plausible mechanism of injury thereto. All vehicles manufactured in and after 1983 must be able to withstand a $21 / 2 \mathrm{mph}$ rear collision without structural damage. However, the bumper standard is a minimum requirement, and many vehicles' bumpers perform at a level greater than that prescribed by FMVSS (Federal Motor Vehicle Safety Standard) 215. Hence simply because there is no visible damage to the rear of the target vehicle does not mean the $\Delta v$ was $\leq 21 / 2 \mathrm{mph}$. One must also consider the possibility that elastic deformation of the bumper cover hid underlying plastic deformation of the energy absorber. In other words, the photographs can prompt one to underestimate the magnitude of impact.

$\Delta v$ is dependent in large part upon kinetic energy of the bullet vehicle ( $\mathrm{KE}=1 / 2$ mass $\mathrm{x}$ velocity 2 ). Understandably, one would be less likely injured when rearended by a motorcycle than a high mass vehicle such as a semi tractor-trailer. Velocity is also an important factor, and since it is squared, assumes greater relative importance at higher speeds. Not surprisingly, collisions occurring at highway or freeway speeds are more likely injurious than those on city streets or in parking lots.

Velocity, however, also incorporates direction as well as speed; and it is important to determine whether a collision occurred from behind, in front, or to one side or the other. Other things being equal, a vehicular occupant is less likely to be injured in a rear impact than when struck from the side, since the facet joints of the spine normally allow greater excursion in flexion and extension than lateral (side) bending. While the seat back and head restraint minimize spinal extension, and generally prevent hyperextension, with an impact from behind, and a shoulder belt limits rebound thoracolumbar flexion, these restraints offer little, if any, protection in a side impact. Furthermore, there is a greater likelihood of direct trauma in the latter. The driver's left side may strike or be struck by the driver's door and/or window; likewise there may be direct injury to the right side of a passenger seated on and struck from the right.

Although accelerations of longer duration are more likely injurious, for a given $\Delta v$, the occupant of a vehicle involved in a longer duration impact, such as an underride or override, is exposed to lower forces. Acceleration is equal to the change in velocity divided by the time over which it occurs $(\mathrm{a}=\Delta \mathrm{v} / \Delta \mathrm{t})$. Force equals mass times acceleration $(\mathrm{F}=\mathrm{ma})$. Hence, with a given $\Delta \mathrm{v}$ but longer time, acceleration is less, as is the force. Compared to a bumper-to-bumper impact, an underride (bullet vehicle sliding underneath the rear of the target vehicle) or override also tends to cause more crush of sheet metal, and energy absorption therein. The energy absorbed is hence no longer available to accelerate a struck vehicle.

Characteristics of the vehicle(s), particularly ability to absorb kinetic energy, are also important determinants of bodily injury. Energy-absorbing bumpers and vehicle crush (if any) dissipate energy that would otherwise be available to accelerate (or decelerate) the subject vehicle and occupant.

Interior features of the vehicle are also important. For example, a passenger in a rearended pickup truck having a solid steel bumper without energy absorbers, and seated on a bench seat unequipped with a head restraint, whose head strikes and breaks the rear window of the cab, or hyperextends over the seat back, would be more likely injured than the occupant of a late model car having a well-cushioned, properly adjusted head restraint and seat back. To minimize or prevent injury a head restraint should be at least as high as the head's center of gravity, located in an adult about $9 \mathrm{~cm}$ (3.5 inches) from its top (approximately the same level as center of the ear). Also, the smaller the backset (distance between the back of the head and the front of the restraint) the better. Backsets over $10 \mathrm{~cm}$ ( 4 inches) are associated with increased symptoms, primarily neck pain, after rearend collisions.

However, for tall drivers an adjustable head restraint in the down position may be worse than none at all. The upper end of a too low head restraint may act as a fulcrum during relative rearward motion of head and accompanying neck extension, concentrating anterior tensile and posterior compression forces at a single level. While the occupant of a seat having no head restraint might be subjected to identical or similar forces, absent the fulcrum, there would be more uniform loading of cervical spine. Distribution of the same force amongst multiple levels, rather than concentration at a single one, decreases the likelihood of injury.

While, as implied above, $\Delta \mathrm{v}$ is probably the single most important determinant of bodily injury, it often difficult to quantify. Sometimes police reports, accident reconstructions, or damage repair estimates provide information in this regard; and photographs are helpful when available. However, in some cases the only objective data available upon which to formulate an estimate of change in velocity is the reported dollar amount of damage to a vehicle. While a far from ideal indicator, $\Delta v$ generally is proportional to dollar damage, given similar vehicles and impact directions. Understandably, the occupant of a car requiring $\$ 1000$ in repairs to its rear would be less likely injured than one in a similar vehicle sustaining $\$ 10,000$ in rearend damage.

Reports of physical symptoms following a collision do not necessarily imply, or reflect the severity of, bodily injury. Pain and other somatic complaints are not simply patho- 
physiologic phenomena, but must be understood in the larger context of the whole person. Whether and how an individual perceives and reports pain, for example, depend on many factors including genetics, cultural background, personality, emotional status, level of arousal, and past experience. Persons with a history of physical, sexual, and/or emotional abuse, particularly during childhood, are known to be predisposed to disproportionate somatic complaints. Expectations that a rearend collision should cause neck pain often become self-fulfilling prophecies. Anxiety, depression, substance abuse, and other psychosocial factors may also cause or worsen physical symptoms. Unemployment is associated with delayed recovery from whiplash. In cases where there is anger and/or potential compensation, the severity, distribution, and duration of complaints often correlate poorly with the mechanism and magnitude of the real or alleged trauma. ${ }^{16-22}$

Individuals with preexisting neuromusculoskeletal pathology, whether degenerative and/or traumatic, with or without immediately preceding symptoms, are also more likely to be symptomatic after a collision.

In summary, conclusions regarding causation and apportionment, evaluation and treatment, disability, and impairment for symptoms and signs following a motor vehicle collision must take into consideration multiple factors including the occupant's preexisting physical and psychosocial status, the mechanism and magnitude of the collision, and a variety of biomechanical variables. Opinions and recommendations based solely upon patient history and physical findings, and perhaps imaging studies, may be ill-informed.

\section{References}

1. Anderson RA, Welcher JB, Szabo TJ, Eubanks JJ, Haight, WR: Effect of braking on human occupant and vehicle kinematics in low speed rear-end collisions. Society of Automotive Engineers, SAE No 980298:1-13, 1998.

2. Kornhauser M: Delta v thresholds for cervical spine injury. Society of Automotive Engineers SP-1174, SAE No. 960093:1-13, 1996.

3. Nahum AM and Gomez MA: Injury reconstruction: the biomechanical analysis of accidental injury. Society of Automotive Engineers SP-1030, SAE No. 940568:69-79, 1994.

4. Roberts VL and Compton CP: The relationship between delta $\mathrm{v}$ and injury. Proceedings of the 37th Stapp Car Crash Conference, SAE No. 933111:35-41, 1993.

5. Robinette RD, Fay RJ, Paulsen RE: Delta v: basic concepts, computational methods, and misunderstandings. Society of Automotive Engineers SP-1030, SAE No. 940915:309-332, 1994.
6. Szabo TJ, Haight WR and Welcher JB: Analysis of Low Speed Collisions. Texas Engineering Extension Service, College Station, 1998, Section 8, page 21.

7. Matsushita T, Sato TB, Hirabayashi K, Fujimura S, Azazuma T, Takatori T: X-ray study of the human neck motion due to head inertia loading. Proceedings of the 38th Stapp Car Crash Conference, SAE No. 942208:55-64, 1994.

8. McConnell WE, Howard RP, Guzman HM, Bomar JB, Raddin JH, Benedict JV, Smith HL, Hatsell CP: Analysis of human test subject kinematic responses to low velocity rear end impacts. Society of Automotive Engineers, SAE No. 930889:21-30, 1993.

9. McConnell WE, Howard RP, Krause R, Guzman HM, Bomar JB, Raddin JH, Benedict JV, Hatsell CP: Human head and neck kinematics after low velocity rear-end impacts — understanding "whiplash." Proceedings of the 38th Stapp Car Crash Conference, SAE No. 952724:215-238, 1995.

10. Severy DM, Mathewson JH, Bechtol CO: Controlled automobile rear-end collisions, and investigation of related engineering and mechanical phenomena. Canadian Services Medical Journal, November:727-759, 1955.

11. Szabo TJ, Welcher JB, Anderson RA, Rice MM, Ward JA, Paulo LR, Carpenter NJ: Human occupant kinematic response to low speed rear-end impacts. Society of Automotive Engineers, SP-1045, SAE No. 940532:23-35, 1994.

12. West DH, Gough JP, Harper GTK: Low speed rear-end collision testing using human subjects. Accident Reconstruction Journal, 5(3):22-26, 1993.

13. Ommaya AK: Biomechanics of head injury: experimental aspects, in The Biomechanics of Trauma, Mahum and Melvin Ed., 245269, 1985.

14. Szabo TJ, Haight WR, Welcher JB: Analysis of low speed collisions course. Texas Engineering Extension Service, 10:8, 1998.

15. Szabo TJ, Welcher JB, Anderson RA, Rice MM, Ward JA, Paulo LR, Carpenter NJ: Human occupant kinematic response to low speed rear-end impacts. Society of Automotive Engineers SP-1045, SAE No. 940532:23-35, 1994.

16. Gargan M, Bannister G, Main C, Hollis S: The behavioral response to whiplash injury. J Bone Joint Surg (Br) 79B:523-526, 1997.

17. Lankester BJ, Garneti N, Gargan MF, Bannister GC: Factors predicting outcome after whiplash injury in subjects pursuing litigation. Eur Spine J 15:902-7. 2006.

18. Linton SJ: A review of psychological risk factors in back and neck pain. Spine 25:1148-1156, 2000.

19. Leclerc A, Niehammer I, Landre M, Ozguler A, Etore P, Pietri-Taleb F: One year predictive factors for various aspects of neck disorders. Spine 24:1455-1462, 1999.

20. Mayou R, Bryant B: Outcome of 'whiplash' neck injury. Injury 27:617-623, 1996

21. Harder S, Veilleux M, Suissa S: The effect of socio-demographic and crash-related factors on the prognosis of whiplash.J Clin Epidemiol; 51:377-384, 1998.

22. Cassidy JD, Carroll LJ, Cote P, Lemstra M, Berglund A, Nygren A: Effect of eliminating compensation for pain and suffering on the outcome of insurance claims for whiplash injury. $N$ Engl J Med 342:1179-86, 2000.

\section{Receive The Guides Newsletter by E-mail}

Join your fellow newsletter subscribers who have chosen both mail and e-mail delivery of The Guides Newsletter. It's easy to request.

Send an e-mail to guidesnewsletter@ama-assn.org with a subject line of "E-mail me the Guides.” 
Continued from page 3

Similarities exist between military personnel and individuals injured in an MVC. Both groups have legally mandated entitlement programs for their injuries and expect they will be restored to full health or compensated for their loss. The number and type of symptoms and resultant disability are directly related to the intensity of psychosocial stressors to which subjects are exposed. ${ }^{12}$ Such stressors abound in both groups.

While the stress of combat clearly exceeds that of normal life, it is usually short-lived. Combat is often described as short periods of terror separated by long bouts of boredom. Many people in our society are exposed to months or years of low to moderate levels of stress. The cumulative effects of sustained low-level stress can be just as devastating to one's psychological defenses as the brief, intense stress of combat. The same erosion of psychological reserves that leads to battle fatigue in the soldier can cause the WAD patient to complain of chronic pain and fatigue. The net effect of these defense mechanisms is that the soldier is removed from the stress of combat, while the WAD patient receives a respite from psychosocial stressors.

It is easy for members of each group to focus unresolved anger over their continued symptoms on forces beyond their control. Soldiers may blame their superiors, the military establishment, the government, or the enemy. WAD patients may blame the negligent driver, medical providers, and/or insurance companies. Blaming others absolves them from any responsibility for their continued symptoms and disability, facilitates perpetuation thereof, and acts as an ego defense. These similarities suggest that the forward treatment model, validated on the battlefield and in the occupational literature, provides a useful method for the prevention and treatment of WAD as well as other compensable injuries and illnesses.

\section{Simplicity}

Simple problems treated in a complex manner become complex problems. The military found that ominoussounding diagnoses, complicated tests, and extensive treatment for fairly minor problems (like battle fatigue) only served to strengthen a soldier's belief he was seriously ill or injured, leading to chronic symptoms and disability. Similarly, WAD patients may get the erroneous impression they are suffering from severe injury. Sophisticated diagnostic tests such as a cervical MRI scan often result in diagnoses that may be of no clinical relevance but confirm the negative messages received from the whiplash culture, and adversely affect the subsequent clinical course. The illeffects of diagnostic "labeling," which refers to the unintended and usually adverse consequences of assigning a diagnostic label to an anxious individual, have long been recognized. For this reason, the military abandoned ominous-sounding labels such as "shell-shock" or "war neurosis," and replaced them with more benign names, such as "battle fatigue" or "combat reaction."
A general rule regarding diagnostic studies is that a test is indicated if knowing the results would cause one to alter treatment. Expensive and sophisticated tests should be avoided unless there is a good chance the results will change the course of care. ${ }^{16}$ Many commonly identified radiological findings occur in the general population with the same or similar frequency seen in whiplash patients. ${ }^{13}$ Exceptions to this are fracture or dislocation occurring in more severe collisions. Since most radiographic findings have little to do with symptoms or outcomes ${ }^{24}$, imaging should be used to rule out serious pathology, but is not required for all MVC patients. ${ }^{14}$ Low back pain research has shown that performing radiographs on symptomatic patients can have a negative effect on the duration and intensity of pain, functioning, and health status. ${ }^{15} \mathrm{~A}$ study of x-rays in 349 patients with low back pain of at least 6 weeks' duration concluded, "Radiography encourages or reinforces the patient's belief that they are unwell and may lead to a greater reporting of pain and greater limitation of activities." ${ }^{26}$ Given the potentially negative effects on pain, functional limitations, and recovery; physicians should be judicious in ordering and reporting radiological findings.

Similar evidence exists for MRI scans. A study of 100 whiplash patients' MRIs found the expected changes of aging with $25 \%$ having degenerative disks and $14 \%$ disc bulges or herniations but no radicular symptoms. ${ }^{16}$ Only one finding, prevertebal edema, was related to the trauma. A follow-up study of asymptomatic individuals who had MRIs 7 years earlier found increased age-related findings on repeat MRI but that these did not predict future or current symptoms. ${ }^{17}$ In general, MRIs correlate poorly with whiplash symptoms in patients without neurological deficit and normal radiographic examination of the cervical spine..$^{18,19}$

The psychosocial aspects of WAD have received considerable attention. ${ }^{28-36}$ A study found the physical and psychological responses to whiplash are established by three months. ${ }^{39}$ The rate of recovery slows noticeably after this time. ${ }^{3}$ This suggests the greatest opportunity to influence recovery is early within the first trimester. Just as every MVC patient does not need X rays and an MRI scan, every patient with delayed recovery of WAD symptoms does not need psychological evaluation. However, clinicians must be sensitive to the possibility of confounding psychological issues. If improvement is not seen within the first month psychological testing and interventions should be considered before behavioral responses to injury are firmly established.

Informing a patient of the suspected pathology is an important step in treatment. However, diagnostic labels often become self-fulfilling prophecies as patients tend to conform to expectations regarding symptoms, disability, etc. Workers told that they had "asymptomatic hypertension," a complicated term for a layperson, demonstrated 
increased absenteeism despite the absence of any hypertension-induced pathology. ${ }^{21}$ Soldiers with battle fatigue fare much worse when given a medical diagnosis than when told they are experiencing a normal reaction to the extreme stress of combat. ${ }^{22}$ Since there is often little identifiable pathology in uncomplicated whiplash, ominous diagnostic terms should be replaced with simple, nonthreatening ones. The Quebec Task Force (QTF) identified five grades, or classifications, of WAD. ${ }^{3}$ These classifications correlate with outcomes, demonstrating their utility. ${ }^{23}$

Barsky has wisely noted, "Attention to a symptom amplifies it, whereas distractions diminish it." ${ }^{24}$ During World War II, the military's use of exotic and complex-sounding treatments such as "narcosynthesis" or electroconvulsive therapy often strengthened a soldier's belief he had significant physical or mental illness. While individual healthcare providers can do little to check the powerful psychosocial influences of a whiplash culture, they can at least do no harm. Deyo suggests physicians share the blame for unnecessary disability claims due in part to unwarranted treatment. "Treatments are often imposed as if desperation were a legitimate clinical indication, circumventing objective evidence, scientific precedent, or attention to consensus guidelines for practice." ${ }^{26}$ Unnecessary testing and treatment focuses a patient's attention on his or her symptoms, causing a tendency to over-react to them.

One of the simplest, safest, and cheapest yet potent treatments clinicians can employ is reassurance. The data of Indahl et al. evaluated two groups of workers with low back injuries. One group had return to work restrictions based on functional testing, while the other was told activity and return to normal activities without restrictions would speed their recovery. ${ }^{27}$ The latter group had higher return to work rates than those given specific work restrictions. Similar results have been seen with whiplash.

Patients instructed to return to normal function as soon as possible demonstrated much better recovery rates than those prescribed a soft cervical collar and rest. ${ }^{3,44-47}$ Patients must be convinced that hurt does not equal harm. The pain following a collision is normal and generally shortlived if the embers of psychosocial factors are not fanned into a raging fire by unwarranted testing and treatment. Interestingly, patients who viewed a 12-minute psychoeducational video in the emergency department (ED) rated their pain $70 \%$ lower, were using $85 \%$ less narcotic medication, had over $85 \%$ fewer ED visits, and had $100 \%$ fewer surgical consultations, highlighting the importance of reassurance. ${ }^{28}$

Although the negative effects of physical inactivity on the body have been repeatedly reported in the medical literature, ${ }^{48-53}$ some physicians commonly prescribe rest and excuse patients from work due to pain complaints following an MVC. This places too much emphasis on discomfort. It suggests whiplash pain is something to be feared and avoided rather than accepted and tolerated until heal- ing occurs. Furthermore, since pain and suffering awards are often calculated using a multiplier of the economic damages, taking a person off work generally increases the size of any settlement or award. If a physician decides subjective complaints and findings such as pain and tenderness are sufficient to authorize occupational disability there is an inherent financial motive to act in an injured manner to ensure a more favorable outcome of any legal proceedings. ${ }^{15}$

Even more often overlooked are the negative psychosocial effects of rest and work absence including increased psychological distress, depression, diminished income, lack of socialization, and loss of work habits. ${ }^{29}$ Adopting the disabled role also gives patients with significant psychosocial stressors a socially acceptable means to avoid unpleasant or stressful situations.

Early return to occupational and avocational activities should be a focus of all treatment efforts. Research has shown that resumption of normal activities improves longterm outcomes in whiplash. ${ }^{3,4750}$ It contradicts the negative messages of the whiplash culture, and facilitates a healthier interpretation of the pain and any other post-MVC symptoms. Patients should also be advised that exercise and movement are required for optimal recovery, and avoiding activity will delay healing. In fact, exercise is one of the most potent treatments for acute WAD and neck pain. $3,55,30$

While prior literature has failed to demonstrate the superiority of any one type of exercise, new evidence suggests isolated isometric strengthening is superior to traditional stabilization exercises, stretching, and aerobic conditioning for chronic neck pain. ${ }^{31}$ Research also suggests a guided exercise program is more effective than a pamphlet or isolated instruction and advice about self-management. ${ }^{47,32}$ In keeping with the principle of simplicity, patients should exercise independently whenever possible; but periodic follow up visits with a clinician well versed in the forward treatment model may enhance the effectiveness of an exercise program.

Consensus guidelines have been developed regarding the use of medications to treat WAD. ${ }^{3}$ Grade I WAD should be treated with simple analgesics. Grades II and III may require analgesics and non-steroidal anti-inflammatory medications, but the drugs should be combined with activity and exercise for the best results. Narcotics may be prescribed for severe pain in Grade III WAD, but should not be used to treat Grade II. Muscle relaxants should generally not be used in the acute phase of WAD I or II because of their depressive side effects. ${ }^{8}$ High dose methylprednisone and psychopharmacological agents are not recommended in WAD of any grade.

Injections are sometimes used to control pain from whiplash. Zygapophyseal (facet) joint(s) may be the pain 
generator in as many as $50 \%$ of patients with chronic whiplash pain. ${ }^{33-61}$ Diagnostic blocks using local anesthetic are a valid technique to identify which, if any, zygapophyseal joints are painful. ${ }^{33}$ Local anesthetic-corticosteroid injections of any joints found to be pain generators are often temporarily palliative. However, like trigger point injections, there is no good evidence that such joint injections improve long term clinical outcomes. ${ }^{3}$ Epidural steroid injections are not recommended for Grade I or II WAD, but may benefit chronic, unresolved radicular pain in Grade III. ${ }^{8}$

Physical medicine (therapy) modalities are commonly used to treat whiplash pain. They often provide partial, temporary symptom relief, but there is little evidence any modality has long term efficacy greater than placebo. Furthermore, given the short duration of benefit, modalities are often used repeatedly, and in so doing become expensive. They are also time consuming, can create dependency, and often distract patients from more effective treatment such as exercise. ${ }^{34}$ Consensus guidelines do not support the use of passive modalities in the treatment of chronic neck pain. ${ }^{3,8,59}$

However, a short course of passive treatments may be justified if providing sufficient symptomatic benefit to permit resumption of function and participation in active treatment (stretching, strengthening, and aerobic conditioning exercises) since the latter can be of sustained benefit. ${ }^{8}$ From a practical standpoint, most patients referred for rehabilitation services expect and demand pain relief modalities. If nothing is done to ease their symptoms they may seek out practitioners who will only provide temporarily palliative passive treatments, often irrespective of the need for active rehabilitation and other effective management strategies. The art of medicine is thus called into play. A brief course of passive modalities may be required to establish trust, maintain the clinical relationship, and facilitate acceptance of and compliance with a timely transition to more effective treatment.

If modalities are used, clinicians should be careful to manage expectations regarding their use and benefits. The focus of treatment should always remain on exercise and returning to normal activities as soon as possible. In keeping with the principle of simplicity, patients should be instructed how to do modalities at home whenever possible. If a patient cannot apply modalities at home, it should be clear from the start they will only be used in the clinic if he or she demonstrates objective evidence of functional progress and compliance with other aspects of the treatment program.

Systematic reviews of the scientific literature have found little evidence to support the use of manipulation to treat whiplash. 3, 8, 35, 36 The reviews found no randomized controlled trials examining manipulation for acute neck pain. A major review of manipulation and mobilization of the cervical spine concluded it provides short-term benefit for neck pain and headaches, but called for more research. ${ }^{65}$ Mobilization has been shown to be as effective as manipulation in treating acute and sub-acute neck pain, with a lower risk of adverse effects. ${ }^{37}$ Some recommend manipulation may be used for Grade I and II WAD, providing there is evidence of continuing improvement, but a Grade III WAD injury demonstrating neurological involvement is a relative contraindication to spinal manipulation. ${ }^{8}$ Furthermore, manipulation is most effective when combined with strengthening exercises for the cervical spine, suggesting the improvement is more related to the exercise than manipulation. ${ }^{38}$ Regardless, repeated manipulation or mobilization over a long period of time without a multidisciplinary team evaluation is not justified. ${ }^{3}$

\section{Proximity}

Proximity refers to the need to maintain patient morale and keep them engaged in meaningful roles. Paradoxically, soldiers with a combat stress reaction treated close to the front do better than those removed from it. ${ }^{44,68-70}$ One front line commander talked of "the miracle that would occur with a man about to crack if you could just get him out of his foxhole and back to the CP [command post] for a few hours. Hot food, hot drink, a chance to warm upthat's what he needed to keep going." ${ }^{39}$ Recovery is facilitated if soldiers suffering from combat exhaustion are treated in this manner and not allowed to adopt a sick role.

Removing an MVC patient from the civilian equivalent of the front lines (work and other normal activity) can have a devastating effect. Someone labeled ill or injured is regarded and treated in ways that often make recovery more difficult. ${ }^{40}$ Friends, family members, and employers become sympathetic, expect less, are more understanding of shortcomings, and make fewer demands, which diminish stress. Now that the patient is no longer working, medical testing and treatment are justified to restore pre-injury work status as quickly as possible. The financial losses associated with occupational disability may cause the patient to contact an attorney who often holds out the promise of lucrative compensation. Within weeks the patient is worse because psychosocial factors, particularly anxiety and/or depression, rather than biological factors, are primarily driving the symptom complex.

Whiplash patients must be kept on the "front lines." Staying at or returning to work is a key part of treating any compensable injury or illness. ${ }^{41-76}$ It helps maintain status, self-esteem, identity, and conditioning; and prevents or minimizes iatrogenic disability. ${ }^{17}$ In most workers' compensation systems there are financial enticements for employers to allow an injured worker to return to work with restrictions, or hire a new employee with limitations. However, these incentives do not exist when an employee is injured in a nonwork-related MVC; and for one or more of several reasons the employer may be unwilling to provide 
modified duty. The employer may be concerned about a workers' compensation claim for aggravation of the vehicular injuries by occupational activities, or that diminished physical capacity might result in new injury to the employee or place a coworker at risk. It may actually cost an employer more to accommodate than temporarily replace an employee injured outside of work.

Nevertheless, it is just as important for whiplash patients to return to work. The vehicle insurer has a vested interest in returning the claimant to work, much as a workers' compensation carrier does in the industrial setting. Financial incentives may be used to entice a collision patient back to work, and diminish the likelihood he or she will adopt a sick role and behave in ways that delay recovery.

Both the unemployed and employed whiplash patient should continue or return as soon as possible to other meaningful roles and activities such as parenting, sports and recreation, hobbies, socializing, and/or participation in religious or service organizations.

\section{Immediacy}

There are critical time periods during recovery from any illness or injury. Healing of tissues typically occurs during known time frames. For example, sprains and strains generally heal in two to four weeks, and fractures in six to eight weeks. When a large influx of injured soldiers arrives at a field hospital, treatment for life-threatening trauma takes precedence, while that for soldiers with minor injuries, or illnesses such as battle fatigue, is appropriately delayed. However, soldiers in the latter group often become refractory to treatment because they did not receive appropriate care during the acute phase of injury or illness when it was critical. During the several days after an MVC, family, friends, acquaintances, and the media often convey negative and inflammatory information concerning whiplash, which instills within the injured occupant negative expectations for recovery. ${ }^{16}$

Just like the soldiers with minor injuries or illnesses who do not receive prompt, appropriate care, failure to intervene appropriately in the first few days after a collision may cause the whiplash patient to develop chronic symptoms refractory to treatment. Consistent with the forward treatment model, healthcare providers should intervene during the acute phase of WAD offering reassurance about the generally benign nature of uncomplicated whiplash along with simple treatments. Patients should be followed closely to ensure symptoms are properly interpreted, questions and concerns addressed expeditiously, and fears and anxieties calmed.

Several critical time periods have been identified following WAD. Nearly everyone involved in a significant MVC will develop head and neck pain. ${ }^{3,5,6,27}$ Most patients return to their previous level of function within one month, though symptoms may persist in some. ${ }^{3,17,42,43}$ A review of 2810 injury claims showed that only $2 \%$ of patients with whiplash alone and $4 \%$ of patients with whiplash combined with other injuries had not recovered by one year. ${ }^{44}$ It is generally accepted that minimal additional improvement can be expected 3 months after a collision. ${ }^{3,39}$ International data suggest that symptoms persisting longer than 6 weeks in Grade I and II injuries should be considered evidence of delayed recovery. ${ }^{13,45}$ At this point, the patient should probably be referred to individuals knowledgeable about the above issues so that all aspects of care can be coordinated and monitored. Nothing is gained by continued treatments without objective evidence of improvement.

\section{Centrality}

As the importance of simplicity, proximity, and immediacy is understood, the need have practitioners skilled in the forward treatment model manage WAD patients during critical time periods becomes apparent. Military medical departments try to ensure all providers with whom an injured soldier comes in contact follow established diagnostic and treatment protocols. Centralized medical management prevents exposure of a soldier to confusing and threatening diagnostic tests, terminology, and treatments. Instead, soldiers tend to get the correct treatment at the right time, decreasing the potential for iatrogenic complications. Unfortunately, those injured in collisions are frequently exposed to unnecessary diagnostic tests and procedures that subtly convey the idea something is seriously wrong. Careless statements and actions by healthcare providers can complicate the clinical picture by reinforcing the negative messages and expectations of the whiplash culture, making the patient less receptive to reassurance and decreasing the chances of a positive outcome. Patients are often bewildered and frustrated by the different opinions about what is wrong and how to address it. They become convinced that not only has something bad happened, but doctors have not found it, and hence are not rendering the correct treatment for the injury. The failure to improve with inappropriate and often excessive treatment is perceived as further evidence of serious underlying pathology, setting the stage for chronic symptoms and disability.

In addition, it is estimated that as many as $36 \%$ of all automobile bodily injury claims have an element of fraud, even though only $3 \%$ involve premeditated criminal acts. ${ }^{15}$ The low rate of premeditated crimes suggests the remaining 33\% are opportunistic acts by doctors, other providers, lawyers, and claimants. ${ }^{15}$ Some practitioners knowingly and willingly perform unnecessary diagnostics tests and treatments to increase their income and perhaps the settlement or award of their patient-claimant. In so doing they not only defraud insurance companies but foster chronic pain and disability rather than recovery. Such healthcare providers may work in collusion with unethical attorneys 
seeking to maximize damages and, thereby their contingency fee. Claimants also play an important role in these schemes, by exaggerating or fabricating symptoms, physical findings, and disability in hopes of obtaining a large financial settlement or award.

Other health care providers may become unwitting accomplices to these fraudulent claims. Physicians are hesitant to damage the doctor-patient relationship by suggesting there is no physical reason for the symptoms. Poor communication between physicians and ancillary health care providers such as physical therapists and chiropractors may permit patients to run up large bills with no, or no sustained, improvement in the factitious symptoms. It also allows evidence of symptom magnification to be overlooked or ignored until it is too late. By contrast, centralized medical management may facilitate earlier identification and documentation of fraudulent claims, minimizing their burden on society.

Centralized medical management is pivotal in gaining control over the epidemic of chronic whiplash symptoms, but is difficult to achieve. Persons having symptoms and/or findings suggesting serious injury at the collision scene are appropriately transported to the nearest emergency room.

MVC occupants without signs of significant pathology (Grade I and II WAD) at the scene are often not transported by ambulance and left to seek treatment on their own. Some end up at an emergency room over the next few days. They are commonly given pain medication, a soft cervical collar, and instructions to see their primary care physician if the symptoms do not resolve in two weeks. Physicians in busy emergency rooms do not have time to provide reassurance about the typically benign nature of whiplash and instruction in self-treatment for the condition, then follow up in a few days to answer any questions that might arise.

A week or two later, after being exposed to the negative influences of the whiplash culture, the patient may see his or her primary care physician and enter the labyrinth of medical care for whiplash. Others seek care from any of a variety of alternative healthcare providers including acupuncturists, chiropractors, etc. Sometimes the first professional contacted is an attorney, who may then refer the new client to a provider.

Centrality is a key to eliminating unnecessary chronic pain and disability, and the societal impact thereof. The military has control the automobile insurer lacks. Soldiers injured on the battlefield do not have the choice of where to go for treatment. The military also has its own hospitals, doctors, and allied health professionals who must follow orders, ensuring that policies and procedures will be routinely followed. Insurance carriers cannot, and probably should not, exert the same level of control over their insureds and claimants. The conflicting interests and motivations of collision patients and insurers make the principle of centrality difficult to implement. The insurance company is concerned with minimizing claim costs, while whiplash patients have their own agendas. However, it is in the best interests of all parties, the WAD patient, insurer, and society as a whole that injured occupants receive appropriate care. The most realistic solution available may be to provide financial incentives to entice collision patients to seek treatment from providers skilled in the forward treatment model.

\section{Expectancy}

Patients tend to fulfill the clinical expectations placed upon them. Militaries found that recovery is inhibited when normal reactions to the extreme stress of combat are labeled and treated as physical maladies. The history of somatic disorders clearly demonstrates that expectations of the medical community shape the symptoms demonstrated as well as their clinical course. ${ }^{46}$ The expectation of pain and disability following an MVC strongly influences the development of chronic symptoms. A two-year follow up of collision patients found that patients who are more concerned about the possibility of long-lasting symptoms or disability have increased risk of chronic complaints. ${ }^{10}$ The more a patient is convinced their symptoms are serious; the more intense, prolonged, and disabling their complaints become. ${ }^{87}$ Significantly lower rates of chronic pain and disability are seen in countries where chronic symptoms are not expected following a collision. ${ }^{13,14,47,48}$

Demolition derby drivers are an example of how expectations can shape post-collision symptoms and recovery. Demolition derby drivers are typically exposed to similar collision forces, but repeatedly, with an average of 48 impacts per event. Many develop neck pain lasting less than 21 days, but very few develop chronic symptoms. ${ }^{49}$ Over a career, the typical demolition derby driver is exposed to 500 collisions — many more than the average driver or passenger, yet again the vast majority of the former group do not develop chronic symptoms. ${ }^{88}$ The neck pain derby drivers experience is a normal, expected result of their chosen activity, and not perceived as a sign of an ominous problem that must receive extensive medical treatment.

Research in Australia showed that managing patient beliefs about low back pain prior to injury resulted in decreased costs and disability. ${ }^{50}$ While such pre-injury education is decidedly more potent than doing so afterwards, giving patients accurate, evidence-based information about the favorable prognosis of uncomplicated WAD postcollision will also help prevent hypervigilance, anxiety, and chronic symptoms.

Unfortunately, some patients do not want to hear about the favorable prognosis for uncomplicated whiplash. 
Involvement in legal proceedings with the potential for sizable financial compensation blunts the effects of reassurance that Grade I and II WAD are benign conditions which usually recover in a matter of weeks. Patients exhibiting pain catastrophizing (an excessively negative orientation to pain) and kinesiophobia (avoidance of movement due to fear of reinjury or aggravation) are so preoccupied with their symptoms and possible worsening thereof they are deaf to the generally favorable outlook for uncomplicated WAD. As Gordon Waddell, et al noted, "The fear of pain and what we do about it may be more disabling that the pain itself." ${ }_{51}$ Anxious patients who receive a respite from the stress of their daily lives after an injury may be reluctant to give up their physical symptoms and return to the way things were before. In those patients who reject reassurance for one or more psychosocial reasons meaningful improvement will not occur until the latter are successfully dealt with. Counseling should be considered those with overly negative expectations for recovery.

Expectations for treatment should be clearly outlined by practitioners to facilitate compliance; and minimize anger, mistrust, and suspicion. First, patients must accept they are responsible for their own recovery. The ultimate cure will not be found in a pill, massage, manipulation, modality, needle, scalpel, or other product or service from a healthcare provider. The patient is the only person who can enact a treatment plan, and each must know that he or she is accountable for compliance with the prescribed care. Patients should also be made aware that failure to comply with treatment may be used by others as evidence they were not really injured or at least are not serious about getting better and hence have failed to mitigate their damages.

Second, the emphasis must remain on active treatment which includes resumption of normal activities. Patients should continue or promptly return to work and/or their usual roles in society whenever possible. Physical medicine modalities, including heat, ultrasound, massage, electrical stimulation, and manipulation, may be used for a short period immediately post-injury and perhaps to manage an exacerbation, but only if consistent, significant, and objectively verifiable progress is seen.

Third, because most whiplash is a simple problem, a sprain and/or strain that should recover in a few weeks without dramatic medical intervention, treatment should be simple as well and for the most part done at home whenever possible. Compliance with the home exercise program should be monitored and documented.

Finally, patients must know that treatment will only continue if they demonstrate objectively verifiable progress, eg, gradually improving range of motion, return to work, etc. If there is no such improvement, they could be considered to have reached maximal medical improvement with cessation of treatment and closure of the claim. Clearly stat- ing expectations at the start of treatment not only benefits patients for reasons stated above, but helps clinicians identify and manage those who fail to meet those expectations and hence are at risk for delayed recovery.

As implied, state-of-the-art treatment for Grade I and II WAD has failed to alter the epidemic of chronic whiplash pain in the United States because it focuses on the biologic rather than biopsychosocial nature of the problem. The prevalent and pernicious whiplash culture in the United States and other western countries shapes a collision patient's symptoms and clinical course even before the impact occurs. It is folly to ignore its influence on uncomplicated WAD. Patients are more than the physical pathology they exhibit, and treatment must address social and psychological factors as well. The forward treatment model provides a framework for evaluating, treating, and managing all aspects of uncomplicated WAD that should improve outcomes for patients and society.

\section{Impairment Evaluation}

Impairment rating is based on appropriate clinical assessment. The physician performing an impairment evaluation must be familiar with the disorder and determine whether appropriate treatment has been rendered, and if inappropriate treatment has contributed to the examinee's perception of the problem.

Parties involved in a claim or lawsuit often want to settle as soon as possible. However, only permanent impairment should be rated. "An impairment is considered permanent when it has reached maximal medical improvement (MMI), meaning it is well stabilized and unlikely to change substantially in the next year with or without medical treatment." (5th ed, 2) If the examinee has no ratable impairment when evaluated, it is probable there will be none even if MMI has not yet been achieved. However, if there are ratable findings, it is essential to wait until MMI because the impairment may not be permanent. The determination of MMI requires careful clinical assessment. As stated, recovery occurs in four to six weeks in most uncomplicated WAD cases. However, for others maximal improvement in symptoms and physical findings such as cervical guarding and motions may take a year from the date of injury. Surgery or intervening injury, exacerbation, or aggravation may delay MMI further.

Impairment assessment for WAD is performed using Chapter 15, The Spine, and must follow the Principles of Assessment in Section 15.1 (5th ed, 374 - 379). The DiagnosisRelated Estimates (DRE) Method is nearly always used to rate WAD since the impairment is attributed to a distinct injury. The Fifth Edition states in Section 15.2, Determining the Appropriate Method for Assessment (5th ed, 379381) "The DRE method is the principal methodology used to evaluate an individual who has had a distinct injury" (5th ed, 379). Box 15-1, Definition of Clinical 
Findings Used to Place an Individual in a DRE Category (5th ed, 382) specifies the symptom (nonverifiable radicular pain), physical findings, and diagnostic tests (electrodiagnostic studies, radiographs, and urodynamic tests) used to select a DRE category. A neck injury is rated according to Section 15.6, DRE: Cervical Spine (5th ed, 393-395) and using Table 15-5, Criteria for Rating Impairment Due to Cervical Disorders (5th ed, 392).

If clinical examination reveals no objective ratable findings, eg, only neck pain and tenderness, there is no ratable impairment. The examinee would fall in DRE Cervical Category I in Table 15-5 (5th ed, 392), having "No significant clinical findings, no observed muscle guarding or spasm, no documentable neurologic impairment, no documented alteration in structural integrity, and no other indication of impairment related to injury or illness; no fractures."

If there are ratable findings at MMI, such as true muscle spasm, guarding, asymmetry of spinal motion, and/or nonverifiable radicular pain (as defined in Box 15-1, [5th ed, 382]), the criteria are met for DRE Cervical Category II. Per Table 15-5 these criteria include "Clinical history and examination findings are compatible with a specific injury; findings may include muscle guarding or spasm observed at the time of the examination by a physician, asymmetric loss of range of motion or nonverifiable radicular complaints, defined as complaints of radicular pain without objective findings; no alteration of the structural integrity." There should be inter- and intraexaminer reliability regarding findings, ie, those noted at the time of impairment rating should be similar to prior evaluations, and reproducible within the same examination. DRE Cervical Category II constitutes 5\% to $8 \%$ whole person impairment (WPI). Selection of the specific percentage impairment from within this and other ranges is based on the extent of interference with activities of daily living.

Most cases of WAD result in a DRE Cervical Category I or II ( $0 \%$ or $5-8 \%$ WPI, respectively). DRE Cervical Category III (15\%-18\% WPI) is assigned for objective evidence of radiculopathy, not for subjective radicular complaints such as pain or numbness. DRE Cervical Category IV (25\%-28\% WPI) requires alteration of motion segment integrity based on radiographic findings as defined in the Guides or significant fracture, and is unusual following whiplash. DRE Cervical Category V (35\%-38\% WPI) requires significant upper extremity neurologic impairment, with or without fracture. This and corticospinal tract injuries, rated via Table 15-6, Rating Corticospinal Tract (5th ed, 396-397) are fortunately rare. They are typically associated with severe trauma and must be supported by significant, objective findings.

Common ratings errors include: assessing impairment prior to MMI, basing the rating on unreliable or inconsistent findings, selecting DRE Cervical Category III based on subjective radicular complaints without objective evidence of radiculopathy, assigning DRE Cervical Category IV on the basis of questionable radiographic studies ${ }^{52}$, use of the Range of Motion (ROM) Method, and including rating of regions of the spine or body not causally related. Often the incorrect rationale for the use of the ROM Method is multilevel degenerative disk disease and/or degenerative arthritis. These common age-related findings do not just justify use of the ROM method.

Ratings of WAD performed by treating physicians are more likely to be erroneous for at least two reasons. First, it is impossible to be independent and difficult to be unbiased in assessing one's own patient. The Guides state impairment rating “. . . is a medical evaluation performed by a physician, using a standard method as outlined in the Guides to determine permanent impairment associated with a medical condition. The physician's role in performing an impairment evaluation is to provide an independent, unbiased assessment of the individual's medical condition." (5th ed, 18) Second, physicians primarily concerned with treatment may not have or take the time necessary to read, understand, and apply the numerous principles, instructions, and criteria for impairment rating listed in the Guides.

\section{Summary}

The physician evaluating and/or treating a whiplash patient needs to have a solid understanding of the complexities and controversies associated with this disorder. Evaluation should be prompt and thorough, but unless indicated avoid sophisticated diagnostic studies. Treatment should generally be simple, and primarily consist of reassurance and home exercise. Disability, both occupational and avocational, should be avoided or minimized. As with other impairment evaluations, the clinical assessment (history, physical examination, and review of diagnostic studies) must be thorough. If there are ratable findings it is essential to determine their reliability and whether the examinee has achieved maximal medical improvement. Most cases of WAD do not result in permanent impairment. When there is ratable impairment it usually falls in DRE Cervical Category II, with a rating of $5 \%$ to $8 \%$ whole person permanent impairment.

\section{References}

1. Blincoe LJ. The economic cost of motor vehicle crashes, 1994. Washington, DC: US Department of Transportation, NHTSA 1996

2. Insurance Research Council. Paying for Auto Injuries: A consumer panel survey of auto collision patients. Oak Brook, IL: Insurance Research Council, 1994

3. Spitzer WO, Skovron MD, Salmi LR, Cassidy JD, Duranceau J, Suissa S, Zeiss E. Scientific monograph of the Quebec Task Force on whiplash-associated disorders: Redefining whiplash and its management. Spine 1995; 20(8S)

4. Hildingsson $\mathrm{C}$, Toolanen G. Outcome after soft tissue injury of the cervical spine. A prospective study of 93 car collision patients. Acta Orthop Scan 1990; 61: 357-359. 
5. Hagstrom Y, Carlsson J. Prolonged functional impairments after whiplash injury. Scand J Rehab 1996; 28: 139-146

6. Hartling et al: A prospective study of acceleration-extension injuries following rear-end motor vehicle collisions. Proceedings of the WAD World Congress, 1999

7. Guidelines for the management of whiplash-associated disorders. Sydney: Motor Collisions Authority, 2001 Jan; 1-43

8. Schrader H, Obelieniene D, Bovim G, Surkiene D, Mickeviciene D, Miseviciene I, Sand T. Natural evolution of late whiplash syndrome outside the medicolegal context. Lancet 1996; 347: 12071211

9. Bonk A, Giebel GD, Edelmann M, Husser RL. Prospective, randomized, controlled study of activity versus collar, and the natural history for whiplash injury in Germany. J Musculoskeletal Pain 2000; 8: 123-32

10. Simotas A, Shen T. Neck pain pain in demolition derby drivers. Presented at the annual meeting of the North American Spine Society, Montreal, 2002; as yet unpublished.

11. Malleson A.Whiplash and other useful injuries. Quebec, Canada McGill-Queen's University Press, 2002

12. Bigos S, Nachemson AL. Work for all: For those with low back pain as well. Clin Orthop 179:77-85, 1983

13. Ferrari R, Russell AS. Pain in the neck for a rheumatologist. Scand J Rheumatol 2000; 29: 1-7.

14. Wang JC, Hatch JD, Sandu HS, Delamrter RB. Cervical flexion and extension radiographs in acutely injured patients. Clin Orthop 1999 Aug; (365) 111-6.

15. Kendrick D, Feilding K, Bentley E, Kerslake R, Miller P, Pringle M. Radiography of the lumbar spine in primary care patients with low back pain: randomized control trial. BMJ 2001; 322:400-405

16. Ronnen HR, de Korte PJ, Brink PRG, van der Bijl HJ, Tonino AJ, Franke CL. Acute whiplash injury: Is there a role for MR Imaging? A prospective study of 100 patients. Radiology 1996; 93-96

17. Back Letter: 13(5), May, 1998.

18. Voyvodic F, Dolinis J, Moore VM, Ryan GA, Slavotinek JP, White AM, Hoile RD, Taylor GW. MRI of car occupants with whiplash injury. Neuroradiology 1997 Jan; 39(1): 35-40

19. Peterson K, Hildingsson C, Toolanen G, Fagerlund M, Bjornebrink J. MRI and neurology in acute whiplash trauma. No correlation in prospective examination in 39 cases. Acta Orthop Scand 1994; 65(5): 525-528

20. Gargan M, Bannister G, Main C, Hollis S. The behavioral response to whiplash injury. J Bone Joint Surg (Br) 1997; 79B: 523-526

21. Haynes RB, Sackett DL, Taylor DW, Gibson ES, Johnson AL. Increased absenteeism from work after detection and labeling of hypertensive patients. New Engl J Med 1978; 299:741,1978.

22. Jones, FD, Hales, RE. Military Combat Psychiatry, Psychiatric Annuals, 17:8/Aug 87, p526.

23. Hartling L, Brison RJ Ardern C, Pickett W. Prognostic value of the Quebec classification of whiplash-associated disorders. Spine 2001; 26(1): 36-41

24. Barsky AJ. Amplification, somatization, and the somatoform disorders. Psychosomatics 1992; 33: 28-34

25. Jones FD, Hales RE. Military combat psychiatry: A historical review. Psychiatric Annals 17:8/August 1987: 526

26. Deyo RA. Pain and public policy. New Eng J Med April 2000; 342(16): 1211-1213

27. Indal A, Velund L, Reikeraas O. Good prognosis for low back pain when left untampered. A randomized clinical trial. Spine 1995; 20:473-477

28. Oliviera A, Gertvitz R, Hubbard D. A psycho-educational video used in the emergency department provides effective treatment for whiplash injuries. Spine 2006; 31: 1652-1657

29. Bortz WM. The disuse syndrome. West J Med 141:691-694, 1984.

30. Peetgers GGM, Verhagen AP, de Bie RA, Oostendorp RAB. The efficacy of conservative treatments in patients with whiplash injury. A systematic review of clinic trials. Spine 200; 26: E74-E73

31. Ylinen J, Esa-Pekka T, Nykanen M, Hakkinen A, Malkia E, Pohjolainen T, Karppi S, Kautiainen H, Airaksinen O. Active neck muscle training in the treatment of chronic neck pain in women. A randomized controlled trial. JAMA 2003; 289: 2509-2516

32. Taimela S, Takala EP, Askol A, Seppala K, Parvianen S. Active treatment of chronic neck pain. A prospective randomized intervention. Spine 2000; 25: 1021-1027

33. Barnsely L, Lord S, Bogduk N. Comparative local anesthetic blocks in the diagnosis of cervical zygapophyseal joint pain. Pain 1993; 55: 99-106

34. Feine JS, Lund JP. An assessment of the efficacy of physical therapy and physical modalities for the control of chronic musculoskeletal pain. Pain, 1997;71:5 23

35. Hurwitz EL, Aker PD, Adams AH, Meeker WC, Shekelle PG. Manipulation and mobilization of the cervical spine. A systematic review of the literature. Spine 1996; 21: 1746- 1759

36. Koes BW, Assendelft WJ, van der Heijden GJ, Bouter LM, Knipschild PG. Spinal manipulation and mobilization for back and neck pain: A blinded review. BMJ 1991; 03(6813): 1298-1303

37. Hurwitz, Morgenstern H, Harber P, Komiski GF, Yu F, Adams AH. A randomized trial of chiropractic manipulation and mobilization for patients with neck pain. Clinical outcomes from the UCLA neck pain study. Am J of Public Health, 2002; 92: 1634-1641

38. Bronfort G, Evans R, Nelson B, Aker PD, Goldsmith GH, Vernon H. A Randomized clinical trial of exercise and spinal manipulation for patients with chronic neck pain. Spine 2001; 26: 788-799

39. Ambrose SE. Citizen Soldiers. 1997; Touchstone. New York, NY 10020

40. Barsky AJ, Borus JF. Functional somatic syndromes. Ann Intern Med 1999; 130: 910-921

41. Dent GL. Curing the disabling effects of employee injury. Risk Manage. 1985; January:30.

42. Smed A. Cognitive function and distress after common whiplash injury. Acta Neurol Scand 1997; 95: 73-80

43. Suissa S, Harder S, Veilleux M. The relation between initial symptoms and signs and the prognosis of whiplash. Eur Spine J 2001; 10: 44-49

44. Harder S, Veilleux M, Suissa S. The effect of sociodemographic and crash-related factors on the prognosis of whiplash. J Clin Empidemiol 1998; 51: 377-384

45. Barsky AJ, Borus JF. Functional somatic syndromes. Ann Intern Med 1999; 130: 910-921

46. Shorter E: From paralysis to fatigue. A history of psychosomatic illness in the modern era. New York, NY, The Free Press, 1992

47. Barsky AJ, Borus JF. Functional somatic syndromes. Ann Intern Med 1999; 130: 910-921

48. Ferrari R, Russell AS. Epidemiology of whiplash-An international dilemma. Ann Rheum Dis 1999; 58: 1-5

49. Ferrari R, Obelieniene D, Russell AS, Darlington P, Gervals R, Green P. Layperson's expectation of the sequelae of whiplash injury. A cross-cultural comparative study between Canada and Lithuania. Med Sci Monit, 2002; 8(11): CR728-734

50. Simotas A, Shen T. Neck pain pain in demolition derby drivers. Presented at the annual meeting of the North American Spine Society, Montreal, 2002; as yet unpublished.

51. Buchbinder R, Jolley D, Wyatt M. Population based intervention to change back pain beliefs and disability: three part evaluation. $B M J$ 2001; 322: 1516-1520

52. Waddell G, Newton M, Henderson I, Somerville D, Main CJ. A Fearavoidance beliefs questionnaire (FABQ) and the role of fear-avoidance beliefs in chronic low back pain and disability. Pain 1993; 52: $157-168$

53. Luers P. Spinal Alteration of Motion Segment Integrity. The Guides Newsletter. March / April 2007, 1. 
The Guides Newsletter is published 6

times a year by the American Medical Association. Subscription rates are $\$ 150$ for AMA members, $\$ 200$ for nonmembers. To order by telephone, call (800) 621-8335. Fax orders should be sent to (312) 464-5600. Mail orders should be sent to Order Department, American Medical Association, PO Box 930876, Atlanta, GA 31193-0876.

Specify product number NG034096

in ordering.

Information contained in this newsletter does not constitute legal or business advice and should not be substituted for the independent advice of an attorney or business consultant. Opinions expressed in articles are not necessarily those of the AMA.

\section{Calendar of Events 2007}

\begin{tabular}{|c|c|c|c|c|}
\hline \multicolumn{2}{|l|}{ e } & Activity & Location & Organization \\
\hline \multicolumn{2}{|c|}{ Ongoing } & $\begin{array}{l}\text { GuidesIQ - AMA Guides Training: The Intelligent Approach } \\
\text { (Internet-based training) }\end{array}$ & www.quidesia.com & BA \\
\hline \multirow[t]{5}{*}{ July } & $14-15$ & $\begin{array}{l}\text { Independent Medical Evaluations - Take the Next Step: } \\
\text { A Seminar on Challenging Issues and Achieving Excellence }\end{array}$ & Chicago, IL & ACOEM \\
\hline & 16 & $\begin{array}{l}\text { Workers' Compensation Legal Issues and Defense Strategies; ADA, } \\
\text { FMLA, and Workers' Compensation: In Depth; Injured and Aging Workers: } \\
\text { Maximizing the Fit Between Worker and Work; Comprehensive } \\
\text { Assessment and Treatment of Chronic Pain: Incomes and Outcomes; } \\
\text { Advanced Presentation and Training Skills Workshop; Work-Related } \\
\text { Upper Extremity Disorders: Achieving Success; Disability Mgmt./Return } \\
\text { to Work: Raising the Bar }\end{array}$ & Hyannis, MA & SEAK \\
\hline & $17-19$ & $\begin{array}{l}\text { 27th Annual National Workers' Compensation and Occupational } \\
\text { Medicine Conference }\end{array}$ & Hyannis, MA & SEAK \\
\hline & 20-21 & Designated Doctor and Physician Training Course & Fort Worth, TX & AADEP \\
\hline & $20-22$ & $\begin{array}{l}\text { ABIME Certification Review and AMA Guides 5th Edition Training } \\
\text { Course; Medicolegal Issues for Independent Medical Examiners; } \\
\text { ABIME Certification Examination }\end{array}$ & Sydney, Australia & ABIME \\
\hline
\end{tabular}

For further information about training and seminars, contact:

AADEP American Academy of Disability Evaluating Physicians

ABIME American Board of Independent Medical Examiners

ACOEM American College of Occupational and Environmental Medicine

BA

Brigham \& Associates, Inc.

SEAK SEAK Legal and Medical Information Systems www.aadep.org www.abime.org www.acoem.org www.impairment.com www.seak.com 